\title{
Cultura impressa: edição, circulação e leitura no Brasil
}

\author{
Gabriel Costa Labanca
}

BRAGANÇA, Aníbal; ABREU, Márcia (Orgs.). Impresso no Brasil. Dois séculos de livros brasileiros. São Paulo: Editora Unesp; Rio de Janeiro: Fundaçâo Biblioteca Nacional, 2011.

A importância do volumoso Impresso no Brasil não se manifesta, apenas, pela qualidade das pesquisas sobre a história editorial brasileira que compóem a obra. Agraciada com o Prêmio Jabuti 2011, na categoria "Comunicação", a coletânea de 35 artigos, ao longo de suas 663 páginas, consolida no país o campo de pesquisas multidisciplinar comumente chamado de "História do livro e da leitura", mas que abrange todo tipo de impresso, popularizado por estudiosos da cultura, como Robert Darnton e Roger Chartier, principalmente a partir da publicação da obra, hoje clássica, $O$ aparecimento do livro, de Henri-Jean Martin e Lucien Febvre, em 1958. No Brasil, apesar de algumas tentativas esparsas realizadas por autores como Eduardo Frieiro e Carlos Rizzini, ainda na década de 1940, um esforço coletivo nessa área será visível somente após a publicação, em 1985, de O livro no Brasil. Sua história, de Laurence Hallewell. Ironicamente, essa que foi considerada, por muito tempo, a obra de referência sobre a história editorial no Brasil foi elaborada por um biblioteconomista inglês como tese de doutoramento, defendida na Universidade de Essex. Embora com algumas lacunas, Hallewell desenvolveu um estudo sistemático e abrangente sobre a circulação de impressos, desde antes da fundação da primeira editora no país. Pesquisadores de diversos campos do conhecimento têm procurado, desde então, complementar, refutar ou corrigir dados e idéias apresentados pelo autor britânico, como é o caso dos colaboradores de Impresso no Brasil, cujos ensaios constituem-se nos frutos amadurecidos e germinados, a partir $\mathrm{da}$ obra de Hallewell.

Para o desenvolvimento desse campo de estudos, entretanto, um esforço conjunto foi ne- cessário, ao longo da última década, para aproximar pesquisadores de diversas áreas das Ciências Humanas, através da organização de publicaçôes e eventos. Neste sentido, não poderiam ser outros os organizadores da coletânea. Márcia Abreu é professora do Departamento de Teoria e História Literária da Unicamp e coordena, desde 2002, o projeto "Caminhos do Romance", integrando docentes das áreas de História e de Letras. Além disso, elaborou e organizou obras de grande relevância para a coleção "Histórias de Leitura". Já Aníbal Bragança, além de ter atuado no mercado editorial, é professor de Comunicação na Universidade Federal Fluminense e coordenador do Núcleo de Pesquisa sobre Livro e História Editorial no Brasil (LIHED), responsável pela organização do Seminário Brasileiro sobre Livro e História Editorial que, em 2004 e 2009, reuniu grande parte dos autores da coletânea. Contudo, a contribuição de ambos não se restringe à organização de eventos e publicações: na obra em questão, Bragança joga uma nova luz sobre os precursores da impressão no Brasil, buscando razóes para a sua tardia implantaçáo que escapam de uma vertente historiográfica engajada, apenas, no combate à metrópole. Enquanto Bragança percorre o longo e tortuoso caminho da imprensa até o Brasil, Márcia Abreu revela quais eram os títulos que saíam de seus prelos, além de traçar um rápido panorama sobre os primeiros editores comerciais do país.

A obra segue o caráter multidisciplinar exigido na análise da edição, circulação e leitura de impressos. Os especialistas nela reunidos vêm de diferentes disciplinas, como Antropologia, Comunicação, Desenho Industrial, Economia, Educação, Filosofia, História e Letras. Infelizmente, o bibliófilo José Mindlin, autor da Introdução da obra, faleceu no início de 2010 e náo pode ver o livro impresso, nem os debates travados por ocasião de seu lançamento na Biblioteca Nacional, em abril do mesmo ano. Um ano antes, outra per- 
da significativa, principalmente para a historiografia da cultura no Brasil, foi a de Sandra Jatahy Pesavento que contribuiu para a coletânea com um interessante exame da vida literária de Porto Alegre, no início do século XX.

A descentralização geográfica, principalmente em relação ao maior centro editorial do país, a cidade do Rio de Janeiro, é outra relevante característica da obra, na medida em que torna possível comparar diferentes contextos, apresentando, assim, um quadro mais nítido da cultura impressa. Neste sentido, Marisa Deaecto guia o leitor pelas ruas da antiga Sáo Paulo da primeira metade do século XIX, mostrando as instituiçóes de leitura da cidade; Elisabeth Torresini incumbe-se de traçar um panorama editorial do Rio Grande do Sul, identificando a emergência de livreiros, livrarias, gabinetes de leitura, bibliotecas e editoras entre os séculos XIX e XX; Denis Bernardes trata da história da tipografia em Pernambuco, na primeira metade do século XIX; Socorro Barbosa analisa o universo editorial da Paraíba do Oitocentos; Luis Guilherme Tavares e Flávia Rosa discorrem sobre a história do livro na Bahia; Maria Luiza Pinheiro discute a ainda mais tardia implantaçáo da imprensa no Amazonas; Felipe Matos procura demonstrar a existência de um comércio literário em Nossa Senhora do Desterro (hoje Florianópolis); e Christianni Morais e Luiz Carlos Villalta realizam um levantamento do perfil das bibliotecas privadas na província de Minas Gerais, entre 1714 e 1874 . Vale assinalar que Villalta vem se destacando, há alguns anos, por suas pesquisas detalhadas na área, principalmente no que tange à posse de livros na Minas Gerais dos séculos XVII e XVIII.

Dividida em duas partes - "Uma nova história editorial brasileira: editores, tipógrafos e livreiros" e "Cultura letrada no Brasil: autores, leitores e leituras" -, Impresso no Brasil enfoca, sobretudo, a figura do editor, ou livreiro-editor, como se caracterizava esse profissional até o início do século XX. Apesar de pequena, a história editorial brasileira está ainda por ser construída e as dificuldades, aqui, são maiores do que as de outros países, uma vez que não há, no Brasil, a tradição de se conservar documentos de livrarias e editoras. Portanto, nada mais adequado do que iniciar a investigação desse território árido pelas editoras mais afamadas, pois que, geralmente, dispóem de uma quantidade maior de material documental. Desse modo, não poderia estar ausente da coletânea uma pesquisa que se debruçasse sobre os catálogos da célebre editora Garnier, com a qual Eliana Dutra permite ao leitor avaliar o que realmente era lido, ou os textos que os editores julgavam, por opçóes ideológicas ou comerciais, que deveriam ser impressos. Isto fica ainda mais claro, quando a antropóloga Alessandra El Far transporta o leitor para o mundo dos livros populares, vendidos por Pedro Quaresma, em sua Livraria do Povo, ao final do século XIX. Tratava-se de publicaçóes, como o próprio editor anunciava, "baratíssimas", que procuravam causar "sensação" nos leitores, através de histórias de terror, crimes, aventuras e, até mesmo, de sensualidade. Ao náo se prender ao gosto "erudito" da crítica literária, El Far aproxima o leitor de um tipo de leitura possivelmente bastante praticada naqueles dias, tanto pelas classes mais abastadas, quanto pelos setores menos instruídos. A leitura popular é também abordada por Ana Maria Galvão, através da história dos folhetos de cordel. Tomando como base as reflexóes de Roger Chartier, a autora analisa a materialidade desses impressos, objetivando identificar as transformaçôes de seu público leitor ao longo do tempo.

Já no século XX, uma figura emblemática para a história do livro e da leitura no Brasil foi a de Monteiro Lobato. Mais conhecido como o criador do universo fantástico do Sítio do Pica-pau Amarelo, Lobato, entretanto, também se distinguiu por seus feitos editoriais, contribuindo para a popularização do livro no país. No entanto, em seu artigo, Cilza Bignotto relativiza algumas ações do editor, consideradas por muitos como "revolucionárias", examinando, com a necessária atenção, as estratégias inauguradas por seus predecessores e as redes sociais que lhe conferiam prestígio. Já Maria Rita Toledo, ao tratar da Companhia Editora Nacional, fundada por Lobato e Octalles Marcondes Ferreira, na década de 1920, focaliza a coleção "Biblioteca Pedagógica Brasileira”. Criada em 1931, sob a direção do educador Fernando Azevedo, a coleção constitui-se, para a 
autora, em ponto de partida para o entendimento do debate sobre a educaçáo, àquela altura, pelo exame da seleção de certos textos publicados em seu âmbito. Essa prática é abordada também por Maria Rita Toledo, quando estuda a Companhia Melhoramentos que, de uma fábrica de papel adquirida ainda no século XIX pelos irmãos alemães Weiszflog, transformou-se em uma das maiores indústrias editoriais do país. Adotando como carro-chefe da empresa a produção voltada para o mercado escolar, seus editores inauguram a "Biblioteca Infantil", coordenada em seu início pelo professor Arnaldo de Oliveira Barreto e, depois de 1926, pelo educador paulista Lourenço Filho, ambos, assim como Fernando Azevedo, representantes do movimento de renovação educacional que disputava espaço no país. Enquanto explorava o mercado infantil e de livros didáticos em São Paulo, Octalles Marcondes Ferreira deixava que o braço carioca da Companhia Editora Nacional - a editora Civilização Brasileira - cuidasse da edição de obras literárias. Este é o tema do ensaio de Guilherme Lima e Ana Sofia Mariz que analisam a atuação política da editora, sob o comando de Ênio Silveira, durante a ditadura instalada em 1964, demonstrando que seu perfil estava longe de ser apenas combativo; na realidade, a maior parte das coleçóes publicadas pela Civilizaçáo Brasileira voltava-se para temas culturais, como cinema, teatro, poesia, filosofia, dentre outros. Silveira, empregado e genro de Marcondes Ferreira, que viria a adquirir, posteriormente, a editora carioca do sogro, foi responsável pela introdução de práticas inéditas no negócio de livros no Brasil.

Numa outra perspectiva, Antonio Hohfeldt desenvolve uma ampla revisão conceitual e histórica em torno da noção de literatura infantil e dos empreendimentos, nessa área, no Brasil. Já Marcia de Paula Razzini, expóe um panorama da "vocaçáo editorial” de São Paulo para publicar obras didáticas, relacionando-a com os movimentos de expansão da educação popular na regiáo. Nesse quadro, além das já citadas editoras Melhoramentos e Companhia Editora Nacional, a autora examina uma série de outras empresas, obras e autores, com o objetivo de elaborar um mapa editorial paulista do livro didático. O movimento da educaçáo pública das primeiras décadas do século $\mathrm{XX}$, em Minas Gerais, também é analisado por Francisca Izabel Maciel, através dos livros de leitura utilizados após a reforma de Francisco Campos.

Ao mesmo tempo em que a coletânea reúne trabalhos que remontam aos precursores da edição no Brasil, também oferece à leitura aqueles que tratam de períodos mais próximos, como o de Teodoro Koracakis, sobre os primeiros 20 anos da Companhia das Letras, completados em 2006. Referência no tratamento técnico de suas obras e objeto de desejo dos autores, a editora consagrou-se pela produção de volumes de grande valor cultural. Contudo, seu editor, Luiz Schwarcz, de acordo com Koracakis, não atingiu esse patamar sem provocar desavenças, ao utilizar sua rede de relaçôes pessoais para facilitar a divulgação de suas obras, como criticou o próprio Ênio Silveira. Por outro lado, tem-se o caso da Editora Abril, analisada por Mateus Henrique Pereira, percorrendo um caminho diverso daquele da Companhia das Letras. Trazida para o Brasil pelo imigrante ítaloamericano Victor Civita, em 1950, a Abril representou a modernizaçáo da atividade editorial no Brasil, pois diversificou suas atividades, produzindo revistas de gêneros variados, fascículos, enciclopédias e coleçóes vendidas em bancas, além de ter sua própria distribuidora, a única, hoje, que abrange todo o território nacional. Pereira assinala que as estratégias de sucesso foram colhidas por Civita no exterior e adaptadas ao mercado brasileiro de bens culturais, transformando a empresa em um conglomerado de entretenimento. Assim, aproveitando-se das transformaçóes sociais e econômicas pelas quais passou o país ao longo da segunda metade do século XX, o autor analisa como a Abril construiu um império editorial em um país com pouca tradição de leitura.

Embora os grandes editores sejam as estrelas que ocupam parte significativa das pesquisas reunidas na obra, há certamente espaço para outros protagonistas, revelados à medida que o campo de estudos da cultura impressa se alarga. Nesta perspectiva, Marília de Araújo Barcellos traz um artigo sobre a atuaçáo das pequenas e médias editoras e suas estratégias de sobrevivência em um mercado controlado por conglomerados editoriais. 
José Castilho Marques Neto e Flávia Garcia Rosa seguem a mesma direção, ao investigar as editoras universitárias que se aventuram no mercado. Outras importantes frentes de estudo do universo editorial são seus espaços de socialização e de consagração, como as bibliotecas, gabinetes de leitura, livrarias e academias literárias. É o caso da Academia Brasileira de Letras, analisada por Joáo Paulo Coelho Rodrigues em um momento de dificuldades financeiras, no início do Novecentos, quando seus "imortais" foram obrigados a abrir mão de certas tradiçóes e a encontrar novas atividades para a sua subsistência. Da mesma maneira, é possível encontrar indícios sobre a circulação editorial de uma época através dos catálogos de uma biblioteca particular, como fez Giselle Venâncio ao investigar a Coleção Eurico Facó, sem deixar de atentar para a materialidade das obras encontradas. Abordar os livros como objetos, considerando que eles são produzidos por outras mãos, além das do escritor, é uma vertente metodológica na História do Livro e da Leitura. E é neste sentido que também prossegue Isabel Cristina Frade, ao elaborar uma análise comparativa dos aspectos gráficos de livros para alfabetização produzidos no Brasil, em Portugal e na França.

Contudo, o ato de imprimir, em folhas de papel, e encadernar certo texto selecionado é um processo complexo que inclui uma série de outros agentes, práticas, estratégias, elementos e conseqüências, felizmente contemplados em Impresso no Brasil. Uma das mais antigas conseqüências da impressão é a sua proibição: a censura. Desde a criação da imprensa, autoridades de todos os níveis preocuparam-se com a disseminação de textos contrários à ordem vigente; não foi diferente ao longo da ditadura instaurada no Brasil em 1964, como mostra Sandra Reimão. A circulação indiscriminada de impressos não tirava apenas o sono das autoridades. Autores e editores queriam, também, ter o direito de propriedade de suas obras garantido contra a reprodução alheia. Esse conceito de "propriedade literária", que nos afeta com força ainda maior hoje, é discutido por Tânia Bessone e Lucia Maria Bastos Pereira das Neves, duas das maiores especialistas na história editorial brasileira do século XIX.
Apesar da ênfase nos "intermediários esquecidos" da história editorial, expressão utilizada por Darnton para classificar os agentes responsáveis pelas fases de seleçáo dos textos até a sua venda em forma de livro, não são deixados de lado fenômenos atuais do mercado editorial, como as aventuras de Harry Potter e as obras de Paulo Coelho, analisados por Silvia Borelli e Richard Romancini respectivamente. Sem a carga crítica que hierarquiza obras e autores segundo critérios, muitas vezes, nebulosos, tenta-se compreender o sucesso alcançado, tanto pelo personagem quanto pelo escritor, através do exame das transformaçóes sociais que possibilitaram alcançarem tal nível de visibilidade. A excepcionalidade de ambos no mercado editorial é ainda mais acentuada pelo diagnóstico negativo, formulado por Fábio Sá Earp e George Kornis, para a economia do livro no Brasil atual. Por fim, estudos de análise textual - que não perdem de vista a materialidade dos impressos, nem seu contexto social - também integram Impresso no Brasil, como o de Marcello Moreira, sobre a nacionalização das letras na América Portuguesa, e de Maria Teresa Cunha, acerca dos livros de bolso da espanhola Corín Tellado e do brasileiro Carlos Zéfiro.

Enganam-se, portanto, aqueles que definem a História do Livro como um campo que apenas acompanha a trajetória de editoras, ou que produz listagens de obras publicadas em certa época. Estudar a cultura impressa é, de fato, o ponto de partida para uma compreensão mais aguda das vertentes culturais que predominaram nas sociedades ocidentais, ou, pelo menos, nos últimos 500 anos, quando os impressos reinaram como principal instrumento de difusáo cultural. Nesse contexto, ainda estamos longe de ter informaçóes mais consistentes sobre a curta história editorial brasileira. Impresso no Brasil, contudo, é mais uma contribuição de peso nessa área. Uma obra de referência valiosíssima e a demonstraçáo de que progressos podem, de fato, ser obtidos através de pesquisas sistemáticas e continuadas. 